\title{
Pengukuran Lingkungan Kerja Fisik dan Operator Untuk Menentukan Waktu Istirahat Kerja
}

\author{
Ari Zaqi Al Faritsy ${ }^{1 *}$, Yohannes Anton Nugroho ${ }^{1 \#}$
}

\begin{abstract}
Physical workings and physiological data of the work operator on the work of human at work. Therefore, it is necessary to design the working environment for operator comfort and work time determinant. The research process by measuring the physical work environment, the operator's physiological data, the determination of time and work break time. The transmitter and the frais are too dark, the temperature is too hot and humid, it is necessary to increase the number of lamps and air ventilation around the lathe and frais operators. Frais machine operators generated CVL of $26.7 \%$ which is still below $30 \%$ then operators of frais machines can not be exposed to work. Lathe operators of CVL results are $31.34 \%$, because the results are in the range of $30 \%-60 \%$ then the lathe operators experience work that result to operator performance. Lathe operators require a break time of 20.85 minutes and the engine operator frais 18.85 minutes.
\end{abstract}

Keywords: physical work environment, rest period, work fatigue.

\begin{abstract}
Abstrak. Lingkungan kerja fisik dan data fisiologis operator berpengaruh terhadap hasil kerja manusia pada waktu bekerja. Oleh karena itu, perlu dilakukan perancangan lingkungan kerja fisik untuk kenyamanan kerja operator dan penentuan waktu istirahat kerja untuk menghindari kelelahan kerja. Proses penelitian dengan melakukan pengukuran lingkungan kerja fisik, data fisiologis operator, penentuan kelelahan dan waktu istirahat kerja. Pencahayaan operator mesin bubut dan frais terlalu gelap, temperatur terlalu panas dan lembab, maka perlu dilakukan penambahan jumlah lampu dan pembuatan ventilasi udara disekitar operator mesin bubut dan frais. Operator mesin frais dihasilkan CVL sebesar 26,7\% yang masih di bawah 30\% maka operator mesin frais tidak mengalami kelelahan kerja. Operator mesin bubut dihasilkan CVL sebesar 31,34\%, karena hasilnya terletak diantara range $30 \%$ - $60 \%$ maka operator bubut mengalami kelelahan kerja yang berakibat kepada penurunan performa operator selama bekerja. Operator mesin bubut membutuhkan waktu istirahat 20,85 menit dan operator mesin frais 18,85 menit.
\end{abstract}

Kata kunci : lingkungan kerja fisik, rest periode, kelelahan kerja.

\section{Pendahuluan}

Kondisi lingkungan kerja adalah semua keadaan yang terdapat di sekitar tempat kerja seperti temperatur, kelembaban udara, sirkulasi udara, pencahayaan, kebisingan, getaran mekanis, bau-bauan, warna dan lainlain berpengaruh secara signifikan terhadap

\footnotetext{
1 Jurusan Teknik Industri, Fakultas Sains dan Teknologi, Universitas Teknologi Yogyakarta, Jalan Glagahsari No. 63 Yogyakarta

*email: ari_zaqi@uty.ac.id

\# email: yohanesanton@uty.ac.id
}

Diajukan: 14-02-2017

Disetujui: 10-11-2017 hasil kerja manusia (Wignjosoebroto, 2008). Pengaruh yang ditimbulkan berupa kelelahan kerja, kecelakaan kerja, konsentrasi menurun, dan ketegangan pada saat kerja (work stress).

Beban kerja akan diukur berdasarkan parameter-parameter fisiologis operator, seperti volume oksigen yang dikonsumsikan, detak jantung, denyut nadi, dan lain-lain. Data fisiologis ini akan memiliki implikasi di dalam perancangan stasiun kerja disamping juga bermanfaat dalam hal penjadwalan kerja (penyusunan waktu istirahat), mengurangi stress akibat beban kerja yang terlalu berlebihan, dan lain-lain. 
Temperatur lingkungan, berat badan, dan tingkat beban kerja mempunyai pengaruh yang signifikan terhadap denyut nadi (Purwaningsih \& Aisyah, 2016). Pemulihan kelelahan kerja perlu dilakukan dan diterapkan istirahat pendek 5-10 menit setiap satu jam kerja (Sundari, 2011). Alokasi waktu istirahat yang sesuai dengan jenis pekerjaan bisa mengurangi nilai level resiko cidera operator saat bekerja (Andriani \& Sugiono, 2016). Waktu istirahat dapat menurunkan denyut nadi kerja operator sehingga tidak terjadi kelelahan kerja (Andriyanto, 2012). Begitu pentingnya penentuan waktu istirahat dalam bekerja untuk mengurangi kelelahan kerja. Penelitian ini bertujuan menentukan waktu istirahat kerja dan \%CVL, serta energy expenditure berdasarkan lingkungan kerja fisik dan data fisiologis operator kerja.

Proses produksi SKU tegangan tinggi menggunakan mesin bubut dan frais. Kedua mesin tersebut berada dalam satu lingkungan kerja yaitu ruangan mesin perkakas, tetapi letaknya berjauhan. Pengukuran lingkungan kerja fisik dan data fisiologis operator bubut dan frais perlu dilakukan untuk menentukan waktu istirahat kerja, sehingga operator bekerja tidak memiliki beban kerja yang berlebihan. Selain itu kondisi lingkungan kerja fisik harus memberikan rasa nyaman dan aman kepada operator. Pengaruh beban kerja berlebihan dan ketidaknyaman kondisi lingkungan kerja fisik dapat menimbulkan operator cepat mengalami kelelahan, stress dan kecelakaan kerja.

\section{Kondisi lingkungan kerja}

Kondisi lingkungan kerja meliputi suhu, kelembaban, getaran, kebisingan, dan lainlain. Stress atau kelelahan kerja bisa terjadi akibat dari kondisi lingkungan kerja yang panas, bising, dan getaran mesin yang berlebihan. Stress atau kelelahan kerja bisa menimbulkan dampak negatif pada performance maupun moral operator.
Suhu yang baik di tempat kerja yang memberikan produktivitas kerja yang tinggi adalah pada temperatur $24^{\circ} \mathrm{C}-27^{\circ} \mathrm{C}$. Pengaruh tingkat temperatur pada tubuh manusia saat bekerja berbeda-beda seperti berikut (Wignjosoebroto, 2008):

$\pm 49^{0} \mathrm{C}$ : Temperatur dapat ditahan sekitar 1 jam, tetapi jauh diatas tingkat kemampuan fisik dan mental.

$\pm 30^{\circ} \mathrm{C}$ : Aktivitas mental dan daya tanggap mulai menurun dan cenderung untuk membuat kesalahan dalam pekerjaan, timbul kelelahan fisik.

$\pm 24^{0} \mathrm{C}$ : Kondisi optimum.

$\pm 10^{0} \mathrm{C}$ : Kelakuan fisik yang extreme mulai muncul.

Kelembaban adalah banyaknya air yang terkandung dalam udara (dalam \%). Suatu keadaan dimana udara sangat panas dan kelembaban tinggi akan menimbulkan pengurangan panas dari tubuh secara besar besaran (karena sistem penguapan) dan semakin cepatnya denyut jantung karena makin aktifnya peredaran darah untuk memenuhi kebutuhan akan oksigen. Menurut Kepmenkes No. 1405 Tahun 2002 batas kelembaban ruangan industri adalah $40 \%$ $60 \%$. Bila kelembaban udara ruang kerja > $60 \%$ perlu menggunakan alat dehumidifier. Bila kelembaban udara ruang kerja < 40\% perlu menggunakan alat humidifier.

Pencahayaan sangat mempengaruhi manusia untuk melihat obyek - obyek secara jelas, cepat tanpa menimbulkan kesalahan. Kemampuan mata untuk melihat obyek dengan jelas ditentukan oleh ukuran obyek derajat kontras antara obyek dengan sekelilingnya, luminasi (brightness), serta lamanya waktu untuk melihat obyek tersebut berdasarkan jenis kegiatannya disajikan pada Tabel 1.

Kebisingan ditimbulkan dari suara yang diluar batas kemampuan pendengaran. Kondisi suara dan batas tingkat kebisingannya disajikan pada Tabel 2. 
Tabel 1. NAB Pencahayaan

\begin{tabular}{|c|c|c|}
\hline Jenis Kegiatan & $\begin{array}{c}\text { Tingkat } \\
\text { Pencahayaan } \\
\text { Minimal (lux) }\end{array}$ & Keterangan \\
\hline $\begin{array}{l}\text { Pekerjaan kasar dan tidak } \\
\text { terus-menerus }\end{array}$ & 100 & $\begin{array}{l}\text { Ruang penyimpanan dan peralatan atau } \\
\text { instalasi yang memerlukan pekerjaan } \\
\text { kontinyu }\end{array}$ \\
\hline $\begin{array}{l}\text { Pekerjaan kasar dan terus- } \\
\text { menerus }\end{array}$ & 200 & $\begin{array}{l}\text { Pekerjaan dengan mesin dan perakitan } \\
\text { kasar }\end{array}$ \\
\hline Pekerjaan rutin & 300 & $\begin{array}{l}\text { Ruang administrasi, ruang kontrol, } \\
\text { pekerjaan mesin dan perakitan }\end{array}$ \\
\hline Pekerjaan agak halus & 500 & $\begin{array}{l}\text { Pembuatan gambar atau bekerja dengan } \\
\text { mesin kantor, pemeriksaan atau } \\
\text { pekerjaan dengan mesin }\end{array}$ \\
\hline Pekerjaan halus & 1000 & $\begin{array}{l}\text { Pemilihan warna, pemrosesan tekstil, } \\
\text { pekerjaan mesin halus dan perakitan } \\
\text { halus }\end{array}$ \\
\hline Pekerjaan sangat halus & $\begin{array}{l}1500 \text { (tidak } \\
\text { menimbulkan } \\
\text { bayangan) }\end{array}$ & $\begin{array}{l}\text { Mengukir dengan tangan, pemeriksaan } \\
\text { pekerjaan mesin, dan perakitan yang } \\
\text { sangat halus }\end{array}$ \\
\hline Pekerjaan terinci & $\begin{array}{l}3000 \text { (tidak } \\
\text { menimbulkan } \\
\text { bayangan) }\end{array}$ & $\begin{array}{l}\text { Pemeriksaan pekerjaan, perakitan } \\
\text { sangat halus }\end{array}$ \\
\hline
\end{tabular}

Tabel 2. Nilai ambang batas kebisingan

\begin{tabular}{ccc}
\hline No. & $\begin{array}{c}\text { Tingkat Kebisingan } \\
(\mathbf{D b})\end{array}$ & $\begin{array}{c}\text { Pemaparan } \\
\text { Harian }\end{array}$ \\
\hline 1. & 85 & 8 jam \\
2. & 88 & 4 jam \\
3. & 91 & 2 jam \\
4. & 94 & 1 jam \\
5. & 97 & 30 menit \\
6. & 100 & 15 menit \\
\hline
\end{tabular}

Sumber : Kepmennaker No. 51 tahun 1999

Berat/ringannya beban pekerjaan yang dilakukan oleh seorang pekerja dapat ditentukan oleh gejala-gejala perubahan yang tampak dan bisa diukur lewat pengukuran anggota tubuh/fisik manusia antara lain:

1. Laju detak jantung (heart rate)

2. Tekanan darah (blood plesure)

3. Temperature badan (body temperature)

4. Laju pengeluaran keringat (sweating rate)

5. Konsumsi oksigen yang dihirup (oxygen consumption)

6. Kandungan kimiawi dalam darah (latic acid content)
Beban kardiovaskular (cardiovascular load) adalah perbandingan antara peningkatan denyut nadi kerja dengan denyut nadi maksimum (Manuaba \& van Worterghem, 1996), beban kardiovaskular dihitung dengan rumus :

\section{$\% C V L$ :}

$100 x$ (demyut nodi ker/a-denyut node istrahat) denyat nad makshum-denyut nad lstrahat

Menghitung denyut nadi maksimum menggunakan rumus yaitu (Astrand \& Rodahl, 1986): 
Denyut nadi maksimum $=220-$ umur

Klasifikasi beban kardiovaskular disajikan pada Tabel 3.

\section{Energi Expenditure}

Metode pengukuran langsung adalah mengukur oksigen yang dikeluarkan (energy expenditure) melalui asupan energi selama bekerja. Lucian Brouha membuat klasifikasi beban kerja berdasarkan konsumsi oksigen, energy expenditure, dan denyut nadi kerja disajikan pada Tabel 4.

Rest periode adalah lamanya waktu istirahat bagi operator dalam selang waktu kerja tertentu. Menurut Murrel rumus untuk menentukan rest periode dalam kerja fisik dihitung menggunakan persamaan (Niebel \& Freivalds, 1999):

$\mathrm{RP}=\frac{\mathrm{t}(\mathrm{w}-\mathrm{s})}{\mathrm{w}-1,5}$

Keterangan:

$\mathrm{t}=$ waktu perjam untuk istirahat (60 menit)

$\mathrm{w}=$ energy expenditure terbesar saat

recovery (cal/menit)

$\mathrm{s}=$ energy expenditure rata-rata (cal/menit)

\section{MetodoloGi}

Penelitian dilakukan pada industri manufaktur logam PT. "X”. Subjek penelitian adalah operator mesin frais dan mesin bubut. Penelitian ini merupakan penelitian observasional pada lingkungan kerja fisik dan data fisiologis operator kerja pada stasiun kerja mesin frais dan mesin bubut.

Pengumpulan data dilakukan secara langsung distasiun kerja mesin frais dan mesin bubut. Objek penelitian terdiri dari 5 operator, yang diukur secara acak 2 orang. Pengukuran kebisingan dengan menggunakan alat ukur sound level meter. Pengukuran pencahayaan menggunakan alat ukur flux meter. Pengukuran kelembaban menggunakan alat ukur humidity meter. Pengukuran suhu menggunakan alat termometer. Pengukuran dilakukan selama dua hari kerja yaitu hari pertama mengukur denyut nadi kerja, pencahayaan, kebisingan, temperatur, dan kelembaban dan hari kedua mengukur denyut nati istirahat. Selain data lingkungan kerja fisik, juga dikumpulkan data umur operator mesin frais dan bubut.

Pengolahan data dimulai dari membandingkan hasil pengukuran

Tabel 3. Klasifikasi beban kardiovaskular (\%CVL)

\begin{tabular}{cl}
\hline$\%$ CVL & \multicolumn{1}{c}{ Klasifikasi } \\
\hline$<30 \%$ & Tidak terjadi kelelahan \\
$30 \%$ s.d $<60 \%$ & Diperlukan perbaikan \\
$60 \%$ s.d $<80 \%$ & Kerja dalam waktu singkat \\
$80 \%$ s.d $<100 \%$ & Diperlukan tindakan segera \\
$>100 \%$ & Tidak diperbolehkan beraktivitas \\
\hline
\end{tabular}

Sumber : Tarwaka, 2010

Tabel 4. Klasifikasi beban kerja

\begin{tabular}{lccc}
\hline \multicolumn{1}{c}{ Work load } & $\begin{array}{c}\text { Oxygen } \\
\text { consumtion }\end{array}$ & $\begin{array}{c}\text { Energi } \\
\text { expenditure }\end{array}$ & $\begin{array}{c}\text { Heart rate } \\
\text { during work }\end{array}$ \\
\hline Light & $0,5-1,0$ & $2,5-5,0$ & $60-100$ \\
Moderate & $1,0-1,5$ & $5,0-7,5$ & $100-125$ \\
Heavy & $1,5-2,0$ & $7,5-10,0$ & $125-150$ \\
Very heavy & $2,0-2,5$ & $10,0-12,5$ & $150-175$ \\
\hline \multicolumn{2}{c}{ Sumber : Niebel \& Freivalds, 1999} & &
\end{tabular}

Sumber : Niebel \& Freivalds, 1999 
kebisingan, cahaya, temperatur, dan kelembaban dengan NAB (nilai ambang batas) yang berasal dari regulasi pemerintah dan literatur. Setelah itu menentukan \%CVL berdasarkan rumus dari Manuaba dan Vanworterghem (1996) dan klasifikasi $\%$ CVL menggunakan tabel yang bersumber dari Tarwaka (2010). Selanjutnya menghitung waktu istirahat kerja dengan menggunakan rumus dari Niebel dan Freivalds (1999).

Langkah terakhir dari penelitian ini adalah melakukan analisis hasil pengolahan data sebelum disimpulkan hasil penelitian. Selain itu pada tahap analisis dilakukan usulan perbaikan untuk kondisi lingkungan kerja fisik yang di atas NAB (nilai ambang batas) yang tidak aman/nyaman untuk operator mesin bubut dan mesin frais.

\section{HASIL DAN PEMBAHASAN}

\section{Pengumpulan dan Pengolahan Data}

Lingkungan kerja fisik yang diukur adalah temperature, kelembaban, pencahyaan, dan kebisingan disekitar mesin frais dan mesin bubut. Hasil pengukuran lingkungan kerja fisik disajikan pada Tabel 5 dan Tabel 6 .

Menghitung kelelahan kerja operator mesin frais dan mesin bubut berdasarkan beban kardiovaskular yang diukur dari denyut nadi operator. Hasil pengukuran denyut nadi disajikan pada Tabel 7.

Beban kardiovaskular dihitung berdasar rumus (1), maka beban kardiovaskular yang dikeluarkan oleh masing - masing operator sebagai berikut:

Tabel 5. Pengukuran Lingkungan Kerja Fisik Mesin Bubut

\begin{tabular}{lccl}
\hline $\begin{array}{c}\text { Lingkungan Kerja } \\
\text { Fisik }\end{array}$ & Hasil Pengukuran & NAB & \multicolumn{1}{c}{ Keterangan } \\
\hline Kebisingan & $80,3 \mathrm{Db}$ & $85 \mathrm{~dB}$ & Di bawah NAB (AMAN) \\
Cahaya & $36 \mathrm{Lux}$ & $300 \mathrm{Lux}$ & Di bawah NAB (Terlalugelap) \\
Temperatur & $29,6^{\circ} \mathrm{C}$ & $28,0{ }^{\circ} \mathrm{C}$ & Di atas NAB (Terlalupanas) \\
Kelembaban & $76 \% \mathrm{RH}$ & $40 \%-60 \%$ & Di atas NAB (TerlaluLembab) \\
\hline
\end{tabular}

Tabel 6. Pengukuran Lingkungan Kerja Fisik Mesin Frais

\begin{tabular}{lccl}
\hline $\begin{array}{c}\text { Lingkungan Kerja } \\
\text { Fisik }\end{array}$ & Hasil Pengukuran & NAB & \multicolumn{1}{c}{ Keterangan } \\
\hline Kebisingan & $77,4 \mathrm{~dB}$ & $85 \mathrm{~dB}$ & Di bawah NAB (AMAN) \\
Cahaya & $21 \mathrm{Lux}$ & $300 \mathrm{Lux}$ & Di bawah NAB ( terlalugelap) \\
Temperatur & $29,9^{\circ} \mathrm{C}$ & $28,0^{\circ} \mathrm{C}$ & Di atas NAB (terlalupanas) \\
Kelembaban & $77,2 \% \mathrm{RH}$ & $40 \%-60 \%$ & Di atas NAB (terlalulembab) \\
\hline
\end{tabular}

Tabel 7. Denyut Nadi Operator Mesin Frais

\begin{tabular}{ll}
\hline \multicolumn{1}{c}{ Objek yang di ukur } & \multicolumn{1}{c}{ Hasil Ukuran } \\
\hline DenyutNadiKerja & 102 Beats/min \\
DenyutNadiIstirahat & 66 Beats $/$ min \\
UsiaPekerja & 19 tahun \\
Denyutnadimaksimal & $220-19=201$ Beats $/ \mathrm{min}$ \\
\hline
\end{tabular}

Tabel 8. Denyut Nadi Operator Mesin Bubut

\begin{tabular}{ll}
\hline \multicolumn{1}{c}{ Objek yang di ukur } & \multicolumn{1}{c}{ Hasil Ukuran } \\
\hline DenyutNadiKerja & 106 Beats/min \\
DenyutNadiIstirahat & 64 Beats/min \\
UsiaPekerja & 22 tahun \\
Denyutnadimaksimal & $220-22=198$ Beats/min \\
\hline
\end{tabular}


Operator mesin frais, $\% \mathrm{CVL}=26,7 \%$.

Operator mesin bubut, $\% \mathrm{CVL}=31,34 \%$.

\section{Waktu Istirahat (rest periode)}

Mengurangi kelelahan kerja selama operator bekerja dengan menentukan waktu istirahat operator selama bekerja untuk menjaga kinerja operator selama bekerja. Waktu istirahat yang diperlukan oleh operator sebagai berikut:

1. Operator bubut

Hasil pengukuran denyut nadi operator bubut disajikan pada Tabel 8 dan klasifikasi beban kerja disajikan pada Tabel 3. Energy expenditure operator mesin bubut selama bekerja diperoleh sebesar 5,6 cal/min. Sedangkan energy expenditure operator bubut selama istirahat adalah 2,75 cal/min. Hasil pengukuran energy expenditure operator mesin bubut disajikan pada Tabel 9. Waktu istirahat yang diperlukan operator mesin bubut adalah 20,854 menit.

2. Operator mesin frais

Hasil pengukuran denyut nadi operator frais disajikan pada Tabel 7 dan klasifikasi beban kerja disajikan pada Tabel 3 . Energy expenditure operator mesin frais selama bekerja diperoleh sebesar 5,2 $\mathrm{cal} / \mathrm{min}$. Sedangkan energy expenditure operator frais selama istirahat adalah $2,875 \mathrm{cal} / \mathrm{min}$. Hasil pengukuran energy expenditure operator mesin frais disajikan pada Tabel 9. Waktu istirahat yang diperlukan operator mesin bubut adalah 18,851 menit.

\section{Kelelahan Kerja}

Kelelahan kerja diukur dari denyut nadi yang dinyatakan dalam $\%$ beban cardiovascular (\%CVL). Pada operator mesin frais dihasilkan CVL sebesar 26,7\%, berdasarkan tabel klasifikasi beban kardiovaskular sebesar 26,7\% masih di bawah 30\% maka operator mesin frais tidak mengalami kelelahan kerja. Operator mesin frais bekerja dalam kondisi normal selama waktu kerja berlangsung dan banyak waktu menganggur.

Pada operator mesin bubut dihasilkan CVL sebesar 31,34\%, karena hasilnya terletak diantara range 30\% - 60\% maka operator bubut mengalami kelelahan kerja yang berakibat kepada penurunan performa operator selama bekerja. Operator mesin bubut membutuhkan waktu istirahat selama bekerja sedang berlangsung.

Hasil pengukuran kondisi lingkungan kerja fisik operator bubut dan operator frais menunjukkan beberapa kriteria masih di bawah NAB seperti cahaya lampu yang terlalu gelap. Pencahayaan yang kurang dapat menyebabkan mata operator kerja cepat lelah, sehingga bisa menimbulkan kesalahan kerja. Selain itu keadaan temperatur yang terlalu panas dan keadaan kelembaban yang terlalu lembab. Kondisi temperature terlalu panas akan mengakibatkan rasa letih dan kantuk, mengurangi kestabilan dan meningkatkan jumlah angka kesalahan kerja (Grandjean, 1986 dalam Nurmianto, 2004). Kondisi lingkungan kerja yang dibawah NAB perlu dilakukan perbaikan untuk kenyamanan dan keselamatan kerja operator mesin bubut dan mesin frais selama bekerja. Untuk keadaan yang terlalu gelap perlu dilakukan penambahan jumlah lampu (cahaya) disekitar operator mesin frais dan bubut. Sedangkan untuk keadaan yang terlalu panas dan lembab perlu dilakukan pembuatan ventilasi udara

Tabel 9. Energy expenditure operator

\begin{tabular}{lll}
\hline \multicolumn{1}{c}{ Energi Expenditure } & \multicolumn{1}{c}{ Mesin Bubut } & \multicolumn{1}{c}{ Mesin Frais } \\
\hline selama bekerja & $5,6 \mathrm{Cal} / \mathrm{min}$ & $5,2 \mathrm{Cal} / \mathrm{min}$ \\
selama istirahat & $2,75 \mathrm{Cal} / \mathrm{min}$ & $2,875 \mathrm{Cal} / \mathrm{min}$ \\
Rata-Rata $(\mathrm{s})$ & $4,175 \mathrm{Cal} / \mathrm{min}$ & $4,037 \mathrm{Cal} / \mathrm{min}$ \\
\hline
\end{tabular}


(sirkulasi udara) dan alat dehumidifier di sekitar operator mesin bubut dan frais.

\section{SiMPULAN}

Hasil penelitian dapat disimpulkan sebagai berikut :

1. Lingkungan kerja fisik stasiun mesin frais dan mesin bubut yang di atas nilai ambang batas adalah temperature dan kelembaban. Sedakan untuk yang di bawah nilai ambang batas adalah pencahaayan. Kondisi lingkungan kerja yang dibawah NAB perlu dilakukan perbaikan untuk kenyamanan dan keselamatan kerja operator mesin bubut dan mesin frais selama bekerja. Untuk keadaan yang terlalu gelap perlu dilakukan penambahan jumlah lampu (cahaya) disekitar operator mesin frais dan bubut. Sedangkan untuk keadaan yang terlalu panas dan lembab perlu dilakukan pembuatan ventilasi udara (sirkulasi udara) dan alat dehumidifier disekitar operator mesin bubut dan frais.

2. Waktu istirahat yang diperlukan oleh operator mesin bubut adalah 20,85 menit. Sedangkan operator mesin frais adalah 18,85 menit

\section{DAFTAR PUSTAKA}

Andriani, D.P.; Sugiono, S. (2016). "Penjadwalan waktu istirahat optimal untuk mengurangi resiko musculoskeletal disorders berdasarkan OCRA Index". Jurnal Ilmiah Teknik Industri, Vol. 15 (2), pp.: $157-167$.

Andriyanto, A.; Bariyah, C. (2012). "Analisis beban kerja operator mesin pemotong batu besar (sirkel $160 \mathrm{~cm}$ ) dengan menggunakan metode 10 denyut”. Jurnal Imiah Teknik Industri, Vol. 11 (2), pp.: 136 - 143.

Niebel, B.; Freivalds, A. (1999). Methods, Standards \& Work Design. USA: McGraw Hill Company.

Purwaningsih, R.; Aisyah, A. (2016). ”Analisis pengaruh temperatur lingkungan, berat badan dan tingkat beban kerja terhadap denyut nadi pekerja ground handling bandara". Jurnal Teknik Industri, Vol. 11 (1), pp.: 15 - 20.

Sundari, K.N. (2011). "Keluhan subjektif pada operator komputer di Unit Pelaksana Teknis - Pengembangan Seni dan Teknologi Keramik dan Porselin Bali”. Jurnal Ilmiah Teknik Industri, Vol. 10 (2), pp.: $88-94$.

Tarwaka. (2010). Ergonomi Industri. Surakarta : Harapan Press.

Wickens, C.D.; Lee, J.D.; Liu, Y.; Becker, S.E.G. (2004). An Introduction to Human Factors Engineering. 2nd edition. New Jersey: Pearson Prentice Hall.

Wignjosoebroto, S. (2008). Ergonomi: Studi Gerak dan Waktu. Surabaya: Guna Widya. 